Check for updates

Cite this: RSC Adv., 2017, 7, 24133

\title{
Fatty acid eutectic mixtures and derivatives from non-edible animal fat as phase change materials $\uparrow$
}

Pau Gallart-Sirvent, (iD a Marc Martín, (D) ${ }^{\mathrm{b}}$ Gemma Villorbina, (D) a Mercè Balcells, (D) a Aran Solé, (D) Camila Barrenche, (D) bd Luisa F. Cabeza (D)*b

and Ramon Canela-Garayoa (D) *a

A set of compounds from non-edible fat waste was prepared and their thermal behavior was studied. The fat was hydrolyzed and crystallized in a simple and robust process to yield palmitic acid-stearic acid (PA-SA) mixtures. The PA-SA mass ratios determined by GC-FID (gas chromatography-flame ionization detection) were similar to those reported for eutectic mixtures of PCMs (phase change materials). DSC (differential scanning calorimetry) results indicated that the melting and solidification temperatures were around $55^{\circ} \mathrm{C}$ and $52{ }^{\circ} \mathrm{C}$ and the latent heat of the crystallized fractions measured was around $180 \mathrm{~kJ} \mathrm{~kg}^{-1}$. The thermal cycling reliability of the eutectic mixtures was also tested during 1000 melting/freezing cycles.

Received 4th April 2017

Accepted 26th April 2017

DOI: $10.1039 / \mathrm{c} 7 \mathrm{ra0} 3845 \mathrm{c}$

rsc.li/rsc-advances
The loss in melting and solidification enthalpies was below $14 \%$ in all mixtures showing a promising behavior for PCM applications. Additionally, the unsaturated fatty acids were recovered and transformed to threo-9,10-dihydroxystearic acid (DHSA) and some of their inorganic salts, which were analyzed by FT-IR (Fourier transform-infrared spectroscopy) and tested for the first time using the DSC technique.

\section{Introduction}

Animal fats are triacylglycerols containing saturated and unsaturated fatty acids. Nowadays, enormous amounts of animal fat are produced annually as a co-product of agroindustrial practices generating crude fatty materials that are difficult to treat and valorize. ${ }^{1,2}$ Since fatty acids present high thermal and chemical stability and high heat capacity, TES (thermal energy storage) applications are considered as a potential solution to revalorize these materials. Thermal energy is stored and released during the phase change process by fatty acids, acting as PCMs, when the surrounding temperature increases or decreases. ${ }^{3}$ Indeed, fatty acids and fatty acid derivatives are considered an alternative to other PCMs, such as paraffin and salt products, with the improvement of being sustainable bio-based materials., ${ }^{3,4}$

Recently, various studies of bio-based organic PCMs from feedstocks have appeared. Such studies were based on commercially available organic compounds..$^{5-9}$ These products

\footnotetext{
${ }^{a}$ Department of Chemistry-DBA Center, University of Lleida-Agrotecnio, Av. Rovira Roure 191, 25198, Lleida, Spain. E-mail: canela@quimica.udl.cat

${ }^{b}$ GREA Innovació Concurrent, INSPIRES Research Centre, University of Lleida, Pere de Cabrera s/n, 25001, Lleida, Spain.E-mail: lcabeza@diei.udl.cat

'Department of Mechanical Engineering and Construction, Universitat Jaume I, Campus del Riu Sec s/n, 12071 Castelló de la Plana, Spain

${ }^{d}$ Department of Material Science and Physical-Chemistry, Universitat de Barcelona, Martí i Franqués 1-11, Barcelona 08028, Spain
}

$\dagger$ Electronic supplementary information (ESI) available. See DOI: $10.1039 / \mathrm{c} 7 \mathrm{ra} 03845 \mathrm{c}$ are partially hydrogenated soy-wax ${ }^{6,7}$ or saturated fatty esters resulting from the hydrogenation of unsaturated fatty acid obtained from several sources. ${ }^{5,8,9}$ The hydrogenation process is essential in these bio-based PCMs whereby they can remain stable during phase change cycles with no risk of oxidation., ${ }^{8,10}$ Unfortunately, the unsaturated fatty acids are converted to the corresponding saturated fatty acids, losing the opportunity of use them in other potential applications. On the other hand, eutectic mixtures of fatty acids have also been prepared from pure commercial fatty acids and have shown satisfactory performance as phase change materials. ${ }^{3,11-13}$ However, no study has addressed the preparation of PCMs based on eutectic mixtures directly recovered from acylglycerols as feedstock. Indeed, near eutectic mixtures of PA-SA and unsaturated fatty acids can be separated hydrolyzing animal fat waste with biocatalysts. ${ }^{14}$

The remaining unsaturated fatty acids could be an excellent starting material to prepare high-value molecules..$^{15}$ In that way, oleic acid has been epoxidated, hydroxylated, and cleaved oxidatively to azealic acid. ${ }^{16-18}$ One of the intermediates of this process, DHSA, also plays an important role as a building block. Recently, it has been used as an ionizable molecule in waterborne polyurethane dispersions ${ }^{19}$ and as a starting material for the preparation of lubricants, ${ }^{20}$ estolides,${ }^{21}$ soaps,${ }^{21}$ deodorant sticks ${ }^{21}$ and shampoos. ${ }^{21}$

The aim of the present study is to determine the actual thermal energy storage capacity as PCM of eutectic mixtures of PA-SA prepared from non-edible animal fat through a simple process involving hydrolysis and crystallization steps. 


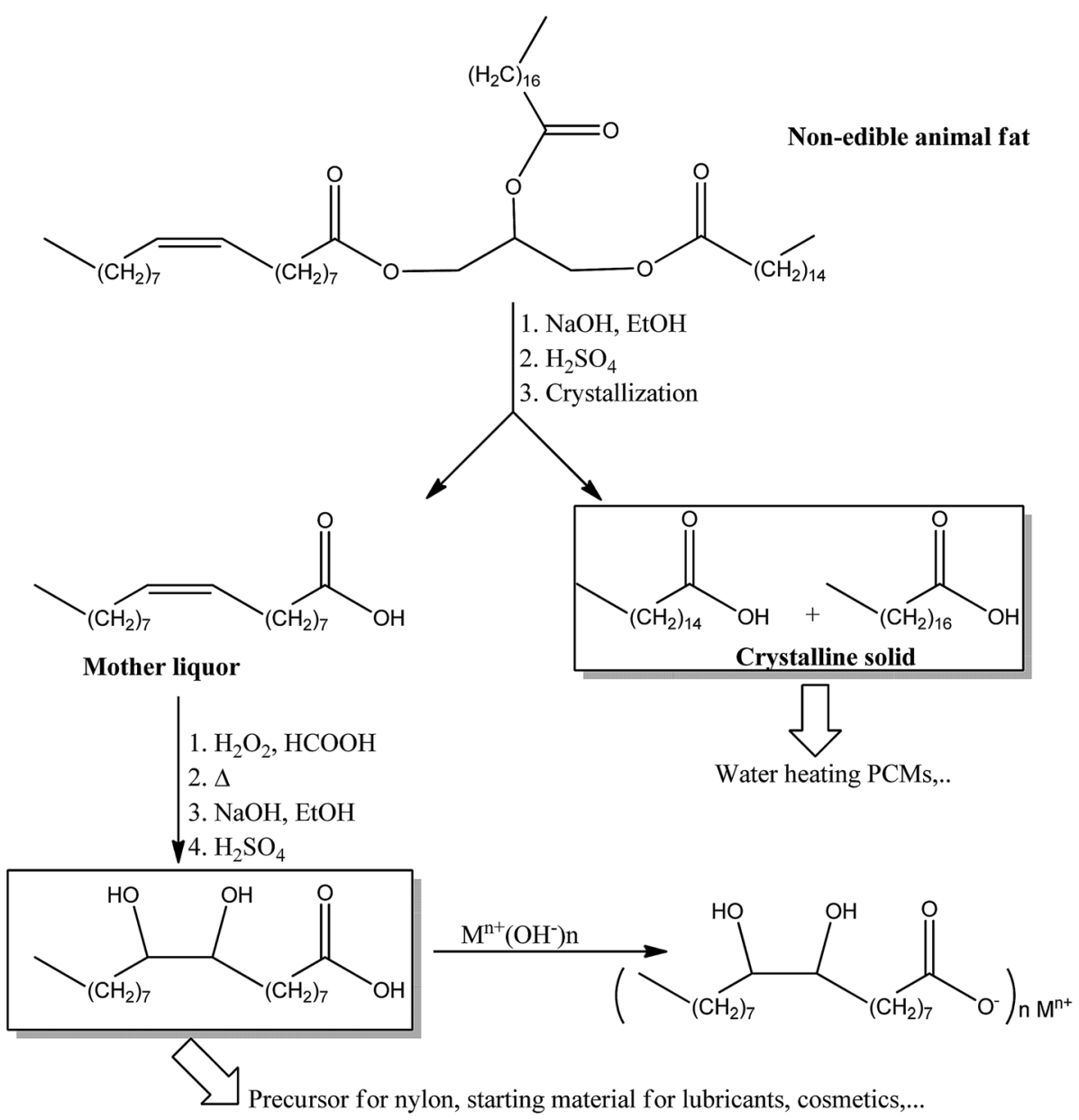

Fig. 1 Synthesis afforded in this study. The triglyceride represents the three fatty acids usable to prepare the products studied.

Moreover, the remaining unsaturated fatty acids were transformed to pure DHSA. DHSA and some of it inorganic salts (Fig. 1) have also been analyzed by FT-IR and tested using a DSC technique to study their potential as PCM.

\section{Experimental}

\subsection{Materials}

Animal fat was a kind gift from Subproductos Cárnicos Echevarria y Asociados S.L (Cervera, Spain). This fat was composed of non-edible fatty pig and chicken parts. It consisted mainly of triglycerides and had a saponification value (SV) of 196. The percentage of unsaturated fatty acids was $55.14 \%$, in which monounsaturated and polyunsaturated fatty acids accounted for $40.50 \%$ and $14.64 \%$, respectively, as determined by a chromatographic method..$^{22}$ Of all the unsaturated fatty acids in the animal fat, oleic acid was the most abundant, accounting for about $36.97 \%$ of the total fatty acids present. Saturated fatty acids accounted for $43.99 \%$ of the total fatty acids and palmitic and stearic acids for $24.57 \%$ and $14.05 \%$ of this total, respectively.

Animal fat hydrolysis and DHSA synthesis were conducted in a mechanically stirred cylindrical jacketed glass reactor (5 L).
Stirring was performed using a stirring glass rod with three Teflon baffles. The reactor temperature was regulated using regular motor antifreeze heated using a B. Braun Thermomix 1441 Recirculating Bath Pump.

\subsection{Synthesis pretreatments}

2.2.1. Non-edible animal fat hydrolysis. Ethanol (1000 mL) was added to the mechanically stirred cylindrical jacketed glass reactor $(5 \mathrm{~L})$ containing $1000 \mathrm{~g}$ of animal fat at $80{ }^{\circ} \mathrm{C}$. The mixture was stirred at $300 \mathrm{rpm}$. Afterwards, $2000 \mathrm{~mL}$ of $14.2 \%$ $\mathrm{NaOH}$ solution at $60{ }^{\circ} \mathrm{C}$ were added drop wise and the reaction mixture was refluxed for $30 \mathrm{~min}$ under stirring. The reaction mixture was driven at $\mathrm{pH}=2$ by adding drop wise $250 \mathrm{~mL}$ of a $98 \% \mathrm{H}_{2} \mathrm{SO}_{4}$. This addition should be performed carefully and drop wise during at least $30 \mathrm{~min}$ to avoid as much as possible the overheating and the organic matter oxidation. Finally, the aqueous layer was discarded and the organic phase was washed twice with $2000 \mathrm{~mL}$ of a $20 \% \mathrm{NaCl}$ aqueous solution at $60{ }^{\circ} \mathrm{C}$. The upper phase was recovered yielding $944 \mathrm{~g}$ of crude free fatty acids (99\% yield).

Crystallization of hydrolyzed animal fat to prepare PA-SA eutectic mixtures and a high unsaturated fatty acid mixture. Crystallization studies were performed by dissolving under 
reflux $5 \mathrm{~g}$ of the hydrolyzed animal fat using various common solvents according the procedure already described. ${ }^{14}$ The crystallization process was performed at $-20{ }^{\circ} \mathrm{C}$ using a solute/ solvent ratio of $1: 6(\mathrm{w} / \mathrm{v})$. Recovered solids were analyzed for their PCMs properties. These solid fatty acids were also analyzed by GC-FID ${ }^{22}$ and FT-IR. To prepare DHSA the crystallization process was scaled up to $200 \mathrm{~g}$ of free fatty acids using methanol at $-20{ }^{\circ} \mathrm{C}$. The mother liquor was concentrated under vacuum to achieve a high unsaturated fatty acid mixture.

2.2.2. Synthesis of DHSA from the high unsaturated fatty acid mixture. The synthesis of DHSA has been widely described appearing as early as end $19^{\text {th }}$ and early $20^{\text {th }} \cdot{ }^{21}$ Swern described on 1959 the synthesis of DHSA from commercial oleic acid. ${ }^{23}$ In this procedure, a high amount of hazardous formic acid and hydrogen peroxide are mixed with oleic acid producing a high exothermic reaction. Once the formic acid is removed by distillation, sodium hydroxide is added to hydrolyze the ester moiety and hydrochloric acid is finally added to liberate the free fatty acids. Recently, the epoxidation and hydrolysis of triacylglycerols $^{\mathbf{2 4 , 2 5}}$ has been described and patented. ${ }^{26}$ These publications studied and optimized the amount of reactants and the conditions to achieve the products using less amounts of reactants and also involving milder conditions. Even though the preparation of crude DHSA from animal sources is claimed, the patented procedure is described and preferred for palm oilbased oleic acid. ${ }^{26}$ These last decades palm oil production has been revised and reviewed due to their contribution in deforestation and their affect in biodiversity. ${ }^{27-29}$ Malaysia and Indonesia produce more than the $80 \%$ of all palm oil. ${ }^{28}$ Unfortunately, 55-59\% of oil palm expansion in Malaysia, and at least $56 \%$ of that in Indonesia occurred at the expense of forests during the period $1990-2005 .{ }^{29}$ Besides, demand of palm oil is predicted to continue increasing ${ }^{30}$ with potentially suitable areas for oil palm cultivation in Southeast Asia, Latin America and Central Africa. ${ }^{28,29}$ In opposite, this study uses non-edible animal fats as a source to prepare DHSA. As a summary, the mixture of high unsaturated fatty free acids recovered from the mother crystallization liquor was mixed with moderate amounts of formic acid and then hydrogen peroxide was added drop wise. ${ }^{24-26}$ Once the double bonds were epoxied, the temperature was increased to lead all the epoxide groups react with the free fatty acids and formic acid yielding the corresponding esters. Subsequently, sodium hydroxide was added to hydrolyze the ester groups and sulfuric acid was finally added to liberate the free fatty acids. ${ }^{23}$ Finally, the crude mixture of reaction was crystallized to recover pure DHSA.

Thereby, $8.32 \mathrm{~mL}$ (208.1 $\mathrm{mmol})$ of formic acid were added to a mechanically stirred cylindrical jacketed glass reactor (5 L) containing $100 \mathrm{~g}$ of the high unsaturated fatty acids previously obtained from the mother liquor. The mixture was stirred at $300 \mathrm{rpm}$. Afterwards, $130 \mathrm{~mL}$ of $30 \% \mathrm{H}_{2} \mathrm{O}_{2}(1.141 \mathrm{~mol})$ solution were added drop wise at $4{ }^{\circ} \mathrm{C}$. Once the addition was finished, the temperature was driven up to $60^{\circ} \mathrm{C}$ and the reaction mixture was stirred for $18 \mathrm{~h}$ at $60{ }^{\circ} \mathrm{C}$. The resulting epoxide groups were hydrolyzed for $3 \mathrm{~h}$ at $100{ }^{\circ} \mathrm{C}$. Ethanol $(100 \mathrm{~mL})$ was added to the reactor, and esters were hydrolyzed by a drop wise addition of $100 \mathrm{~mL}$ of $20 \% \mathrm{NaOH}$ solution at $60{ }^{\circ} \mathrm{C}$. The reaction mixture was stirred under reflux for $30 \mathrm{~min}$ and afterwards driven at $\mathrm{pH}$ $=2$ by adding drop wise $25 \mathrm{~mL}$ of $98 \% \mathrm{H}_{2} \mathrm{SO}_{4}$. The aqueous layer was discarded and the organic phase was washed twice with $300 \mathrm{~mL}$ of a $20 \% \mathrm{NaCl}$ aqueous solution at $60^{\circ} \mathrm{C}$. The crude DHSA was recovered yielding $106 \mathrm{~g}$ (95\% yield). The crude was dissolved in hot ethyl acetate ( $1 \mathrm{~g}$ of solute : $1 \mathrm{~mL}$ of solvent) and let to crystallize for $24 \mathrm{~h}$ at $4{ }^{\circ} \mathrm{C}$. The resulting white powder was recovered by filtration under vacuum in a Pyrex crucible no. 3 and then washed three times with cold ethyl acetate (74\% isolated yield). Mp: $94.5{ }^{\circ} \mathrm{C}$ (DSC first cycle). The final white powder was analyzed by FT-IR and ${ }^{1} \mathrm{H}$ NMR (see ESI $\dagger$ ):

${ }^{1} \mathrm{H}$ NMR (400 MHz, $\left.\mathrm{CDCl}_{3}\right) \delta \mathrm{ppm}: 0.88\left(\mathrm{t}, J=6.9 \mathrm{~Hz}, \mathrm{CH}_{3}\right)$, 1.19-1.55 (m, $\left.\mathrm{CH}_{2}\right), 1.63\left(\mathrm{~m}, \beta \mathbf{C H}_{2}\right), 2.34\left(\mathrm{t}, J=7.4 \mathrm{~Hz}, \alpha \mathrm{CH}_{2}\right)$, $3.40(\mathrm{~m}, \mathbf{H C O H})$.

2.2.3. Synthesis of DHSA salts. To a solution containing $1 \mathrm{~g}$ (3.16 mmol) of DHSA in $10 \mathrm{~mL}$ of methanol, $3.32 \mathrm{mmol}$ of $\mathrm{NaOH}$ or $\mathrm{LiOH} \cdot \mathrm{H}_{2} \mathrm{O}$ in $10 \mathrm{~mL}$ of water were added under high stirring speed. Afterwards, the reaction temperature was increased until the solution became transparent and then let it cold until precipitated appeared. The calcium and magnesium salts were prepared from the sodium salt solution by adding drop wise $3.48 \mathrm{mmol}$ of $\mathrm{CaCl}_{2}$ or $\mathrm{MgCl}_{2}$ in $10 \mathrm{~mL}$ of water. The precipitates were recovered by filtration under vacuum in a Pyrex crucible no. 3. All the products were analyzed by FT-IR.

\subsection{Characterization}

FT-IR spectroscopy was performed in order to identify the characteristic structure of PA-SA eutectic mixture, DHSA and DHSA salts. FT-IR spectra were recorded with a Jasco 6300 FT-IR spectrometer coupled with an ATR accessory.

The DHSA structure and purity was determined by ${ }^{1} \mathrm{H}$ NMR spectroscopy. This technique allowed the evaluation of the purity of this product by comparing the signals related to $\mathbf{H}_{-}$ $\mathrm{COH}$ (hydrogen bonded to a secondary alcohol) and $\mathrm{R}_{1} \mathrm{CH}_{2}$ $\mathrm{COOH}$ (hydrogen bonded to the $\alpha$-carbon of the carboxylic acid). ${ }^{31}$ Moreover, this technique was also used to evaluate the DHSA content after this product was analyzed by DSC technique. ${ }^{1} \mathrm{H}$ NMR spectra were recorded with a MERCURY plus NMR Spectrometer Systems VARIAN Imant AS operating at 400 $\mathrm{MHz}$.

GC-FID is commonly used on the analysis of mixtures of free fatty acids to determine the percentage of each fatty free acid. GC-FID was used to characterize the fatty acid contents in the non-edible animal fat, the PA-SA eutectic mixtures and the high unsaturated fatty acid mixture. These fatty maters were analyzed in triplicate using a ThermoQuest series 2000 chromatograph equipped with a FID detector, an EEP system (Fisons, Barcelona, Spain), a split/split-less injection system and an autosampler. The analytical column (Supelco, Madrid, Spain) was a $30 \mathrm{~m} \times 0.25 \mathrm{~mm}$ fused-silica capillary coated with $0.25 \mathrm{~mm}$ film thickness of poly(80\% biscyanopropyl-20\% cyanopropylphenyl siloxane) (SP-2330), and was temperature programmed from $150{ }^{\circ} \mathrm{C}$ to $220{ }^{\circ} \mathrm{C}$ at $5{ }^{\circ} \mathrm{C} \min ^{-1}$ then held at $220{ }^{\circ} \mathrm{C}$ for $6 \mathrm{~min}$.

Thermophysical characterization was performed with differential scanning calorimetry (DSC 822e from Mettler 
Toledo) in order to analyze the phase change temperature and phase change enthalpies (melting and solidification). Measurements were conducted using a three cycle program repetitions. The first cycle was disregarded and, thus, the mean value of the two following cycles was calculated and the results were presented in a confidence interval of 95\%. The second and the third cycle were performed at $0.5{ }^{\circ} \mathrm{C} \mathrm{min}{ }^{-1}$ under flowing 80 $\mathrm{mL} \min ^{-1}$ nitrogen gas. The DSC analyses were performed between $30{ }^{\circ} \mathrm{C}$ and $250{ }^{\circ} \mathrm{C}$ depending on the melting point of the product studied. The mass of sample used was around $5 \mathrm{mg}$ and the samples were located into $40 \mu \mathrm{L}$ aluminum crucibles. The equipment accuracy was $\pm 0.1{ }^{\circ} \mathrm{C}$ for temperature and $\pm 3 \mathrm{~kJ}$ $\mathrm{kg}^{-1}$ for enthalpy results.

The thermal cycling reliability is crucial for the application of PCMs, in fact only a thermal stable phase change temperature and latent heat of PCMs after a large number of thermal cycles makes possible the PCMs purpose. To study the thermal cycling reliability, an accelerated thermal cycle experiment was performed to analyze the changes of the phase change temperature and latent heat of the PA-SA eutectic mixtures after 1000 thermal cycles. In order to study the thermal cycling stability and reliability, new material samples were cycled in a thermal cycler Bioer Gene Q T-18. A tube volume of $0.5 \mathrm{~mL}$ was used for each compound. A dynamic method was established using a temperature range between 30 and $70{ }^{\circ} \mathrm{C}$ and at $4{ }^{\circ} \mathrm{C} \mathrm{s}^{-1}$ for cooling and $5{ }^{\circ} \mathrm{C} \mathrm{s}^{-1}$ for heating. A total of 1000 cycles were performed under the described conditions. Finally, the compounds were recovered and a new DSC test was performed. Notice that this study presents results when performing 1000 cycles, which would be around 3 years of operation if the PCM implemented in a system cycled once per day. ${ }^{32}$

\section{Results and discussions}

\subsection{FT-IR characterization of the PA-SA eutectic mixture, DHSA and their salts}

Table 1 shows the assigned wave number $\left(\mathrm{cm}^{-1}\right)$ of the compounds synthesized. PA-SA eutectic mixture FT-IR spectra shows a band signal at $2955 \mathrm{~cm}^{-1}$ associated to the asymmetrical stretching vibration of $-\mathrm{CH}_{3}$ while the bands at $2917 \mathrm{~cm}^{-1}$ and $2845 \mathrm{~cm}^{-1}$ responds to the symmetrical and asymmetrical stretching modes of $-\mathrm{CH}_{2}$ group, respectively. A characteristic band at $1697 \mathrm{~cm}^{-1}$ represents the asymmetrical stretching vibration $\left(\omega_{2}\right)$ of $\mathrm{C}=\mathrm{O}$. The band at $1460 \mathrm{~cm}^{-1}$ is the $-\mathrm{CH}_{2}$ deformation while $1409 \mathrm{~cm}^{-1}$ has its origin in the $\mathrm{C}=\mathrm{O}$ symmetrical stretching vibration $\left(\omega_{1}\right)$. The band at $1295 \mathrm{~cm}^{-1}$ represents $-\mathrm{CH}_{2}$ twist and wag and the band at $935 \mathrm{~cm}^{-1}$ responds to $\mathrm{C}=\mathrm{O}$ deformation $\left(\omega_{3}\right)$. The $-\mathrm{CH}_{2}$ rocking vibration and bending is associated to a band at $721 \mathrm{~cm}^{-1}$.

The bands at $3332 \mathrm{~cm}^{-1}$ and $3244 \mathrm{~cm}^{-1}$ correspond to DHSA (O-H stretching vibration). A characteristic band signal at 2952 $\mathrm{cm}^{-1}$ responds to the asymmetrical stretching vibration of $-\mathrm{CH}_{3}$ while the bands at $2910 \mathrm{~cm}^{-1}$ and $2848 \mathrm{~cm}^{-1}$ are associated with the symmetrical and asymmetrical stretching modes of $-\mathrm{CH}_{2}$ group, respectively. The band at $1704 \mathrm{~cm}^{-1}$ is the characteristic absorption band for asymmetrical stretching vibration $\left(\omega_{2}\right)$ of $\mathrm{C}=\mathrm{O}$. The band at $1468 \mathrm{~cm}^{-1}$ corresponds to the $-\mathrm{CH}_{2}$ deformation while $1411 \mathrm{~cm}^{-1}$ respond to the $\mathrm{C}=\mathrm{O}$ symmetrical stretching vibration $\left(\omega_{1}\right)$. The bands at $1331 \mathrm{~cm}^{-1}$ and $1295 \mathrm{~cm}^{-1}$ have its origins on the $-\mathrm{OH}$ bending and $-\mathrm{CH}_{2}$ twist and wag, respectively. The $-\mathrm{OH}$ stretching is associated with a band at $1078 \mathrm{~cm}^{-1}$. At $923 \mathrm{~cm}^{-1}$ and $721 \mathrm{~cm}^{-1}$ are observed the $\mathrm{C}=\mathrm{O}$ deformation $\left(\omega_{3}\right)$ and $-\mathrm{CH}_{2}$ rocking vibration and bending, respectively.

The broad absorption band of $\mathrm{O}-\mathrm{H}$ stretching vibration band is present in all the salts within $3300 \mathrm{~cm}^{-1}$ and $3266 \mathrm{~cm}^{-1}$ depending on the salt. The band corresponding to the asymmetrical stretching vibration of $-\mathrm{CH}_{3}$ is only observed in calcium $\left(2952 \mathrm{~cm}^{-1}\right)$ and sodium $\left(2950 \mathrm{~cm}^{-1}\right)$ spectra salts. Otherwise, the bands at $\sim 2920 \mathrm{~cm}^{-1}$ and $\sim 2850 \mathrm{~cm}^{-1}$ associated to the symmetrical and asymmetrical stretching modes of $-\mathrm{CH}_{2}$ group are present in all spectra. The band at $1704 \mathrm{~cm}^{-1}$ characteristic for asymmetrical stretching vibration $\left(\omega_{2}\right)$ of $\mathrm{C}=\mathrm{O}$ previously observed in DHSA spectra can now be found at the region around $1600-1535 \mathrm{~cm}^{-1}$ upon formation of the carboxylate anion. Moreover, calcium salt spectra presents two

Table 1 Absorption maxima $\left(\mathrm{cm}^{-1}\right)$ in the FT-IR spectra of PA-SA eutectic mixture, DHSA and their salts (see ESI)

\begin{tabular}{|c|c|c|c|c|c|c|}
\hline \multicolumn{6}{|c|}{ Wave number $\left(\mathrm{cm}^{-1}\right)$} & \multirow[b]{2}{*}{ Assignment } \\
\hline $\begin{array}{l}\text { PA-SA } \\
\text { eutèctic }\end{array}$ & DHSA & $\begin{array}{l}\text { Lithium salt } \\
\text { of DHSA }\end{array}$ & $\begin{array}{l}\text { Sodium salt } \\
\text { of DHSA }\end{array}$ & $\begin{array}{l}\text { Calcium salt } \\
\text { of DHSA }\end{array}$ & $\begin{array}{l}\text { Magnesium salt } \\
\text { of DHSA }\end{array}$ & \\
\hline- & 3332,3244 & 3284 & 3290 & 3266 & 3300 & Broad absorption of $\mathrm{O}-\mathrm{H}$ stretching vibration \\
\hline 2955 & 2952 & - & 2950 & 2952 & - & $\mathrm{CH}_{3}, \mathrm{C}-\mathrm{H}$ asymmetrical stretching \\
\hline 2917 & 2910 & 2916 & 2917 & 2917 & 2920 & $\mathrm{CH}_{2}, \mathrm{C}-\mathrm{H}$ asymmetrical stretching \\
\hline 2845 & 2848 & 2847 & 2848 & 2848 & 2852 & $\mathrm{CH}_{2}, \mathrm{C}-\mathrm{H}$ symmetrical stretching \\
\hline 1697 & 1704 & 1562 & 1558 & 1571,1535 & 1600 & $\mathrm{C}=\mathrm{O}$ asymmetrical stretching vibration $\left(\omega_{2}\right)$ \\
\hline 1460 & 1468 & 1463 & 1463 & 1464 & 1468 & $\mathrm{CH}_{2}$ deformation \\
\hline 1409 & 1411 & 1399 & $1435-1415$ & 1428 & 1399 & $\mathrm{C}=\mathrm{O}$ symmetrical stretching vibration $\left(\omega_{1}\right)$ \\
\hline - & 1331 & 1335 & 1328 & 1325 & 1335 & $\mathrm{O}-\mathrm{H}$ bending \\
\hline 1295 & 1295 & - & - & - & - & $-\mathrm{CH}_{2}$ twist and wag \\
\hline- & 1078 & 1078 & 1078 & 1078 & 1078 & O-H stretching \\
\hline 935 & 923 & - & - & - & - & $\mathrm{C}=\mathrm{O}$ deformation $\left(\omega_{3}\right)$ \\
\hline 721 & 721 & 718 & 718 & 718 & 721 & $-\mathrm{CH}_{2}$ rocking and bending \\
\hline
\end{tabular}


bands for the asymmetrical stretching vibration $\left(\omega_{2}\right)$ of $\mathrm{C}=\mathrm{O}$ (1571 and $1535 \mathrm{~cm}^{-1}$ ). The band at around $1460 \mathrm{~cm}^{-1}$ characteristic for the $-\mathrm{CH}_{2}$ deformation and the band at around 1400$1430 \mathrm{~cm}^{-1}$ for the $\mathrm{C}=\mathrm{O}$ symmetrical stretching vibration $\left(\omega_{1}\right)$ are present in all the spectra. As the $-\mathrm{OH}$ bending and $-\mathrm{OH}$ stretching, which have its origins in bands at $\sim 1330 \mathrm{~cm}^{-1}$ and $1078 \mathrm{~cm}^{-1}$, respectively. Finally, the band corresponding to the $\mathrm{C}=\mathrm{O}$ deformation $\left(\omega_{3}\right)$ observed in the previous fatty free acids analyzed disappears in all the salts but the $-\mathrm{CH}_{2}$ rocking vibration and bending is maintained at $\sim 720 \mathrm{~cm}^{-1}$.

\subsection{Composition, thermal properties and reliability of the PA-SA eutectic mixture prepared by crystallization}

The preparation of a eutectic mixture from PA-SA allows of the preparation of PCMs useful in applications such as to improve the thermal comfort in buildings through heating applications, to improve domestic hot water (DHW) tanks efficiency, ${ }^{33,34}$ air conditioning condensation heat recovery systems, ${ }^{3}$ and low temperature industrial waste heat (IWH) recovery. ${ }^{35}$ Depending on the application, palmitic acid and stearic acid present too high phase change temperatures $\left(T_{\mathrm{m}}\right)$. Eutectic mixtures allow the decrease of the $T_{\mathrm{m}}$. In this case, the animal fat used showed a $3: 2$ palmitic/stearic acid ratio $(\mathrm{w} / \mathrm{w})$. This ratio is very close to the palmitic/stearic acid ratio showing eutectic properties, which can lead to the PCM indicated above. ${ }^{3,36}$ Hence, authors realized that by an optimal crystallization, the unsaturated fatty acids and the saturated fatty acids could be separated with the advantage of prepare in the crystallization process an eutectic PA-SA mixture. ${ }^{14}$ Table 2 shows the thermal properties of the PA-SA eutectic mixtures. The solute/solvent ratio and crystallization temperature implied higher saturated fatty acid recovery with no presence of unsaturated fatty acids. In these conditions, between 76 to $90 \%$ of the palmitic and stearic acids present in the starting hydrolyzed animal fat were recovered in form of eutectic mixtures.

The palmitic/stearic acid ratios determined by GC-FID ${ }^{22}$ ranged from $63.2: 36.8$ for the ethyl acetate crystallization to
$58.7: 41.3$ in the case of the methanol crystallization. Similar compositions as $62: 38$ (ref. 3) or $64.2: 35.8$ (ref. 36) were described in the preparation of eutectic mixtures starting from commercially pure palmitic and stearic acids. The DSC curve of the bio-based mixtures prepared from non-edible fats showed one sharp endothermic peak during the melting process and one sharp exothermic peak on the solidification process, which indicates that only one real eutectic mixture has been obtained after crystallization. The melting and solidification temperatures around $55{ }^{\circ} \mathrm{C}$ and $52{ }^{\circ} \mathrm{C}$, respectively, measured by DSC analysis were lower than the melting points of the pure palmitic or stearic acids. ${ }^{3}$ These results were close to those reported on the preparation of PA-SA eutectic mixtures of commercial palmitic and stearic acids, with melting points of $53.89^{\circ} \mathrm{C}$ (ref. 3) and $52.3{ }^{\circ} \mathrm{C}$ (ref. 36) and a solidification temperature of $54.37^{\circ} \mathrm{C}^{3}$ The latent heats of melting of the eutectic mixtures prepared ranged from $183 \mathrm{~kJ} \mathrm{~kg}^{-1}$ to $176 \mathrm{~kJ} \mathrm{~kg}^{-1}$ and the solidification latent heats from $181 \mathrm{~kJ} \mathrm{~kg}^{-1}$ to $172 \mathrm{~kJ} \mathrm{~kg}^{-1}$ depending on the mixture achieved (see ESI $\dagger$ ). Similar results of latent solidification heat, $177.67 \mathrm{~kJ} \mathrm{~kg}^{-1}$ (ref. 3) and $181.7 \mathrm{~kJ}$ $\mathrm{kg}^{-1},{ }^{36}$ were described in the PA-SA eutectic mixtures prepared from commercial palmitic and stearic acids.

In general terms, after thermal cycling, solidification and melting enthalpies present similar reduction in their values with a maximum decrease of $14 \%$ (Table 2). These loses are below $15 \%$ after thermal cycling, which indicated that the material shows good thermal cycling stability. ${ }^{37}$ Moreover, phase change temperature (i.e. melting and solidification) does not present outstanding changes, ranging from -1.8 to $1.1 \%$. According to the distinct mixtures prepared, the product crystallized in methanol presented the best thermal cycling stability since melting enthalpy only decreased by $9 \%$ and solidification enthalpy by $11 \%$ while the ones crystallized in ethanol present the worst (14\% reduction). Moreover, the mixtures crystallized in methanol showed the highest latent heat after 1000 heating/ cooling cycles of the whole materials under study: $164 \mathrm{~kJ} \mathrm{~kg}^{-1}$ (melting enthalpy), $158 \mathrm{~kJ} \mathrm{~kg}^{-1}$ (solidification enthalpy). Thus,

Table 2 Thermal properties of the various PA-SA eutectic mixtures prepared from the hydrolyzed animal fat waste by crystallization with various solvents

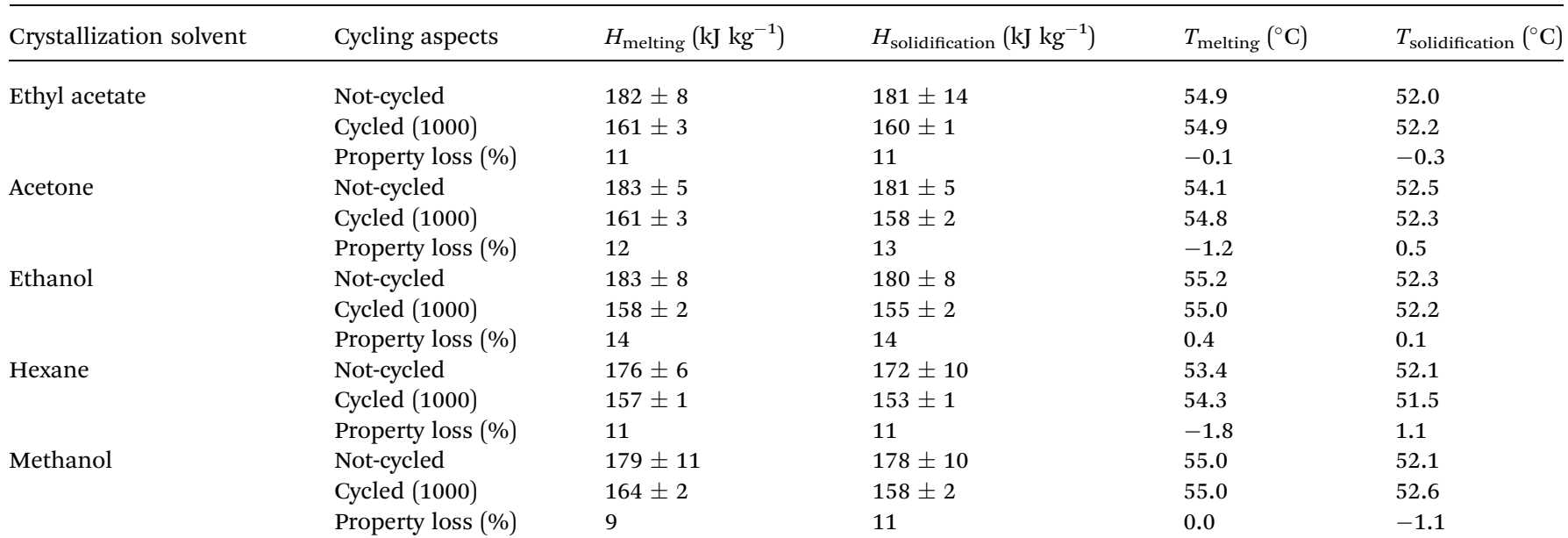


Table 3 Thermal properties of DHSA and their salts

\begin{tabular}{lllll}
\hline Product & $H_{\text {melting }}\left(\mathrm{kJ} \mathrm{kg}^{-1}\right)$ & $H_{\text {solidification }}\left(\mathrm{kJ} \mathrm{kg}^{-1}\right)$ & $T_{\text {melting }}\left({ }^{\circ} \mathrm{C}\right)$ & $T_{\text {solidification }}\left({ }^{\circ} \mathrm{C}\right)$ \\
\hline DHSA & $161 \pm 11$ & $151 \pm 7$ & 93.8 & 82.8 \\
Lithium salt of DHSA & 236 & - & 231.6 & - \\
Sodium salt of DHSA & 82 & - & 204.7 & - \\
Calcium salt of DHSA & $76 \pm 2$ & $68 \pm 4$ & $160 \pm 1$ & $127 \pm 1$
\end{tabular}

these mixtures prepared in an easy and robust process can be considered as potential PCM candidates due to their thermal performance and thermal cycling stability and reliability.

\subsection{Determination of the thermal properties of DHSA and their salts}

Table 3 shows the thermal properties of DHSA and their salts prepared from the animal fat waste. The variation of enthalpy and melting point observed along the two recorded cycles announced the poor cycling stability of DHSA. Presumably, the diol and carboxylic acid moieties present in DHSA reacted forming an estolide with a decreasing response on the enthalpies as well as a modification on the phase change temperature. To confirm this hypothesis, the content in the DSC crucible was recovered and analyzed by ${ }^{1} \mathrm{H}$ NMR spectroscopy (see ESI $\dagger$ ). Two new signals appeared at $3.58 \mathrm{ppm}$ and $4.83 \mathrm{ppm}$, which can be assigned to $\mathbf{H}-\mathbf{C O H}$ (hydrogen bonded to a secondary alcohol) and $\mathrm{R}_{1} \mathrm{COOCHR}$ (hydrogen bonded to a secondary alcoxyester), respectively. These signals are characteristics of a DHSA-estolide. ${ }^{38}$ Nevertheless, the first DSC analysis cycle recorded a melting temperature of $94.5^{\circ} \mathrm{C}$ (ref. 39) and also the narrow enthalpy peaks observed made patent that the developed process allowed the preparation of pure DHSA. Therefore, the worthy melting enthalpy on the first recorded cycle $\left(168 \mathrm{~kJ} \mathrm{~kg}^{-1}\right)$ and a phase change temperature higher than common fatty acids are remarkable. These values are promising for PCM interests but the low cycling stability makes patent the need of avoid the formation of the detected DHSA-estolides.

The DHSA salts were synthesized presupposing the maintenance of the good enthalpy values of DHSA and trying to improve the poor cycling stability. Nevertheless, Table 3 shows that none of the salts synthesized presented a suitable behavior to be used as PCMs. Only calcium diol salt shows melting and solidification, but with a low phase change enthalpy value, whereas magnesium salt does not show melting process. Unfortunately, lithium salt, which showed a very promising melting enthalpy value $\left(236 \mathrm{~kJ} \mathrm{~kg}^{-1}\right)$, did not shown solidification capability.

\section{Conclusion}

This paper shows new applications to non-edible animal fat waste by preparing eutectic mixtures of PA-SA. These compounds were achieved from animal fat by a conventional hydrolysis (99\% yield) process. Various solvents can be used to perform the crystallization process. This let to recoveries up to $90 \%$ of the PA-SA content in the animal fat. These eutectic mixtures of PA-SA showed good performance as PCMs. The melting and solidification temperatures of the various PA-SA PCM prepared were around $55{ }^{\circ} \mathrm{C}$ and $52{ }^{\circ} \mathrm{C}$, respectively. Moreover, the latent heats of the crystallized fractions ranged 172 to $181 \mathrm{~kJ} \mathrm{~kg}^{-1}$. Thermal cycling test results indicated a good thermal cycling reliability of PA-SA because the melting and solidification temperatures of PA-SA PCM oscillated only up to $1.8 \%$ and $1.1 \%$, respectively. Concerning the melting and solidification latent heats of the eutectic PCM, they decreased up to $14 \%$ after 1000 thermal cycles in the most pronounced case. Moreover, DHSA was synthesized from non-edible animal fat. This dihydroxy fatty acid was prepared from the unsaturated fatty acids present in the mother crystallization liquor, which evidences the opportunity of provide distinct applications to animal fat. The DSC analysis performed for first time on DHSA and their salts revealed no potential use as PCM. Nevertheless, a good melting enthalpy and a phase change temperature higher than common fatty acids could be promising for PCM interests. The modification of DHSA to new phase change materials with improved cycling stability is now undergone.

\section{Abbreviations}

$\begin{array}{ll}\text { ATR } & \text { Attenuated total reflectance } \\ \text { DHSA } & \text { threo-9,10-Dihydroxystearic acid } \\ \text { DHW } & \text { Domestic hot water } \\ \text { DSC } & \text { Differential scanning calorimeter } \\ \text { FT-IR } & \text { Fourier transform-infrared spectroscopy } \\ \text { GC-FID } & \text { Gas chromatography-flame ionization detector } \\ \text { IWH } & \text { Industrial waste heat } \\ \text { PA-SA } & \text { Palmitic acid-stearic acid } \\ \text { PCM } & \text { Phase change material } \\ \text { TES } & \text { Thermal energy storage }\end{array}$

\section{Acknowledgements}

GREA and DBA are certified agents TECNIO in the category of technology developers from the Government of Catalonia. We thanks to Subproductos Cárnicos Echevarria y Asociados S.L (Cervera, Spain) for supplying the non-edible fat. Moreover, the research leading to these results has received funding from the European Commission Seventh Framework Programme (FP/ 2007-2013) under grant agreement no. PIRSES-GA-2013-610692 (INNOSTORAGE) and from the European Union's Horizon 2020 research and innovation program under grant agreement no. 657466 (INPATH-TES). The authors would like to thank the 
Catalan Government for the quality accreditation given to their research groups GREA (2014 SGR 123), Agricultural Biotechnology Research Group (2014 SGR 1296) and DIOPMA (2014 SGR 1543). This work has been partially funded by the Spanish government (CTQ2015-70982-C3-1-R (MINECO/FEDER), ENE2015-64117-C5-1-R (MINECO/FEDER) and ENE2015-64117C5-2-R (MINECO/FEDER)). Dr Camila Barreneche would like to thank Ministerio de Economia y Competitividad de España for her grant Juan de la Cierva FJCI-2014-22886. Aran Solé would like to thank Ministerio de Economía y Competitividad de España for Grant Juan de la Cierva, FJCI-2015-25741.

\section{References}

1 K. Ramani, L. John Kennedy, M. Ramakrishnan and G. Sekaran, Process Biochem., 2010, 45, 1683-1691.

2 M. Adamczak and W. Bednarski, Process Biochem., 2004, 39, 1347-1361.

3 N. Zhang, Y. Yuan, Y. Du, X. Cao and Y. Yuan, Energy, 2014, 78, 950-956.

4 M. M. Farid, A. M. Khudhair, S. A. K. Razack and S. Al-Hallaj, Energy Convers. Manage., 2004, 45, 1597-1615.

5 S. Yu, S. G. Jeong, O. Chung and S. Kim, Sol. Energy Mater. Sol. Cells, 2014, 120, 549-554.

$6 \mathrm{~W}$. Hu and X. Yu, Renewable Energy, 2014, 62, 454-458.

7 W. Hu and X. Yu, RSC Adv., 2012, 2, 5580-5584.

8 S. G. Jeong, O. Chung, S. Yu, S. Kim and S. Kim, Sol. Energy Mater. Sol. Cells, 2013, 117, 87-92.

9 S. G. Jeong, J. H. Lee, J. Seo and S. Kim, Int. J. Heat Mass Transfer, 2014, 71, 245-250.

10 J. Kosny, E. Kossecka, A. Brzezinski, A. Tleoubaev and D. Yarbrough, Energy Build., 2012, 52, 122-131.

11 Y. Yuan, N. Zhang, W. Tao, X. Cao and Y. He, Renewable Sustainable Energy Rev., 2014, 29, 482-498.

12 N. Zhang, Y. Yuan, Y. Yuan, T. Li and X. Cao, Energy Build., 2014, 82, 505-511.

13 Y. Yanping, T. Wenquan, C. Xiaoling and B. Li, J. Chem. Eng. Data, 2011, 56, 2889-2891.

14 P. Gallart-Sirvent, E. Yara, G. Villorbina, M. Balcells, N. Sala and R. Canela-Garayoa, J. Mol. Catal. B: Enzym., 2016, 134, 172-177.

15 A. Godard, S. Thiebaud-Roux, P. De Caro, E. Vedrenne and Z. Mouloungui, Ind. Crops Prod., 2014, 52, 111-117.

16 A. Kulik, A. Martin, M.-M. Pohl, C. Fischer and A. Köckritz, Green Chem., 2014, 16, 1799-1806.

17 A. Kulik, A. Janz, M. M. Pohl, A. Martin and A. Köckritz, Eur. J. Lipid Sci. Technol., 2012, 114, 1327-1332.
18 V. Benessere, M. E. Cucciolito, A. De Santis, M. Di Serio, R. Esposito, F. Ruffo and R. Turco, J. Am. Oil Chem. Soc., 2015, 92, 1701-1707.

19 P. P. KosheelaDevi, T. I. Tuan Noor Maznee, S. S. Hoong, H. Nurul'Ain, S. M. Norhisham, M. N. Norhayati, A. Srihanum, S. K. Yeong, A. H. Hazimah, V. Sendijarevic and A. Sendijarevic, J. Appl. Polym. Sci., 2016, 133, 1-10.

20 J. Filley, Bioresour. Technol., 2005, 96, 551-555.

21 G. F. L. Koay, T. Chuah, S. Zainal-abidin, S. Ahmad and T. S. Y. Choong, J. Oleo Sci., 2011, 265, 237-265.

22 J. Eras, F. Montañes, J. Ferran and R. Canela, J. Chromatogr. A, 2001, 918, 227-232.

23 D. Swern, J. T. Scanlan and G. B. Dickel, Org. Synth., 1959, 39, 15.

24 P. K. Gamage, M. O'Brien and L. Karunanayake, J. Natl. Sci. Found. Sri Lanka, 2009, 37, 229-240.

25 F. E. Okieimen, C. Pavithran and I. O. Bakare, Eur. J. Lipid Sci. Technol., 2005, 107, 330-336.

26 S. Ahmad, R. Awang, H. A. Hassan, M. N. Sattar, H. S. Soi and Y. A. Yusof, Palm oil-based hydroxyl fatty acids, EP Pat., 001588999A2, 2005.

27 D. L. A. Gaveau, S. Wich, J. Epting, D. Juhn, M. Kanninen and N. Leader-Williams, Environ. Res. Lett., 2009, 4, 19.

28 E. B. Fitzherbert, M. J. Struebig, A. Morel, F. Danielsen, C. A. Brühl, P. F. Donald and B. Phalan, Trends Ecol. Evolut., 2008, 23, 538-545.

29 L. P. Koh and D. S. Wilcove, Conserv. Lett., 2008, 1, 60-64.

30 C. Carter, W. Finley, J. Fry, D. Jackson and L. Willis, Eur. J. Lipid Sci. Technol., 2007, 109, 307-314.

31 Y. Wu, A. Li and K. Li, J. Am. Oil Chem. Soc., 2015, 92, 111120.

32 A. Sari, Energy Convers. Manage., 2003, 44, 2277-2287.

33 L. F. Cabeza, A. Castell, C. Barreneche, A. De Gracia and A. I. Fernández, Renewable Sustainable Energy Rev., 2011, 15, 1675-1695.

34 T. Kousksou, P. Bruel, G. Cherreau, V. Leoussoff and T. El Rhafiki, Sol. Energy, 2011, 85, 2033-2040.

35 S. Brückner, S. Liu, L. Miró, M. Radspieler, L. F. Cabeza and E. Lävemann, Appl. Energy, 2015, 151, 157-167.

36 G. Baran and A. Sari, Energy Convers. Manage., 2003, 44, 3227-3246.

37 A. Solé, H. Neumann, S. Niedermaier, L. F. Cabeza and E. Palomo, Energy Procedia, 2014, 48, 436-439.

38 R. Awang, A. Azizan, S. Ahmad and W. Yunus, J. Oil Palm Res., 2007, 19, 350-355.

39 D. Swern and E. F. Jordan, J. Am. Chem. Soc., 1945, 67, 902903. 